\title{
Climate Change in Four News Magazines: 1989-2009
}

\section{William Tillinghast San Jose State University, USA Marie McCann San Jose State University, USA}

\begin{abstract}
This longitudinal study examined how four news magazines, The Economist from Great Britain, Mclean's of Canada, and two American publications, Newsweek and U.S. News and World Report, portrayed climate change during six separate years, four years apart, a 20-yearperiod (1989-2009), focusing on what frames were used, did they change over time, and were their differences by publication. Major findings are that the publications did not differ from each other, but all four eventually eliminated the term "greenhouse effect" in favor of climate change to go along with global warming. The magazines also changed from their initial episodic, or isolated theme-oriented story structure to a broader, and more connected, thematic form. The dominant frame throughout the 20 years was political. The scientific frame diminished over time and the ecological-meteorological virtually disappeared.
\end{abstract}

Planet Earth is getting warmer, partly because of human activity, according to the Intergovernmental Panel on Climate Change (IPCC, 2010) and this may lead to changes in vegetation and crop productivity as well as droughts, storms and higher sea levels threatening the survival of coastal cities. This disastrous environmental shift has been on the public agenda for some 50 years and is becoming more of a topic for public concern, as both individuals and governments consider its consequences. It therefore becomes a major news story as well as a major political issue (Carvalho \& Peterson, 2009). 
Although not all agree as to likely effects of global warming, most scientists agree that it is occurring. The Nationals Aeronautics and Space Administration notes that carbon dioxide is now higher, some 390 parts per million, than it has been in more than 800 thousand years (Climate Change, 2010) and the Pew Center for of Global Climate Change suggests that without changes, the earth's temperature could rise by 10 degrees Fahrenheit by the end of this century (climateactionreserve.org, 2010).

Underlying this lack of agreement are various political, economic and social concerns, all of which are based on differences of opinions as to causes, solutions -- even as to whether it is occurring. The vested interests of particular groups lead to different interpretations and often intentional different presentations to the final decision-maker, the public. The public ultimately will determine what actions are to be taken, if any, based on public understanding of the topic. Much of that understanding will be based on how the issue is presented. In other words, what aspects are included and emphasized and what are left out. In other words, how it is framed for the audience.

This study focuses on the framing of the changing news coverage of this changing environment over a 20-year period in four news magazines: The Economist from the United Kingdom, Mclean's from Canada, and two American publications, Newsweek and U.S. News and World Report. The focus is: how was the issue described? Did the publications differ in their framing? and did the frames change between 1989 and 2009 ?

\section{Climate Change}

Prior to the industrial age, the amount of carbon dioxide in the atmosphere was relatively stable and as late as 1900 was only about 290 parts per million. It then began an steady upward climb to the point that in 2012, it is only slightly less than 400 parts per million. In 1900, the Earth's average temperature was 58 degrees Fahrenheit. The average is now 59 degrees. It will increase by at least one more degree by the end of the $21^{\text {st }}$ Century, even if governments and business curtail the bulk of current fossil fuel emissions, because past emission has sufficiently warmed the oceans. If not stabilized, increased fuel emissions, the cause of 75 percent of human-caused emissions, could increase temperatures by four to eight degrees. 
One of the most disastrous effects that could occur if fuel emissions do not decrease will be the impact on the oceans. As carbon dioxide in the atmosphere helps prevent heat from escaping, it gradually warms the oceans which then expand. The additional increase in temperature also increased glacial melting, such as in Antarctica and Greenland. Depending on the extent of melting, the increase in sea level could be between six and 20 feet or even more, devastating most of the world's coastal cities.

One might ask how does science know what future climate is going to be. First, climate specialists are certain that the planet has gotten warmer over the past 100 years (MarquartPyatt et al., 2011). Second, scientists have measured the increase in the amount of heattrapping gases in the atmosphere from human activities, such as the burning of fossil fuels. Third, they know how these gases are causing the observed warming. As a result, the earth is getting warmer.

\section{Framing}

While a vast body of framing literature exists, Entman's (1993) definition of framing will be used.

Entman wrote: To frame is to select some aspects of a perceived reality and make them more salient in a communicating text in such a way as to promote a particular problem, definition, causal interpretation, moral evaluation, and/or treatment recommendation for the item described. (p. 52). Put simply, framing is the act of defining issues - typically by elites - for public consumption, and disseminating these definitions through the use of mass media (Berinsky \& Kinder, 2006).

In the case of climate change, the inclusion of both sides - or fair and balanced coverageprovides a more complete picture by providing audiences with alternative information, but at the expense of a scientific consensus (Antilla, 2005; Boykoff \& Boykoff, 2007; Smith, 2005). Framing happens regardless of intention. Entman (1993) wrote that "journalists may follow the rules for 'objective' reporting and yet convey a dominant framing of the news text that prevents most audience members from making a balanced assessment of a situation" (p. 57). Even the most ethical and objective reporters will inherently introduce cultural biases. 
Cultural values also affect how costs and benefits will be assigned to a particular news story. It is because of frames that causes are diagnosed and moral judgments are assigned (Entman, 1993). With regard to complex issues such as the environment, the reporter or news organization often assigns moral judgments and values.

\section{Publications}

The strength of news magazines lies in their in-depth coverage on issues. More detailed information, in-depth coverage and an analytical view of events is available in news magazines because of their weekly news cycle, unlike those of newspapers or television (Griffin, 2004). And overall, news magazines provide more contextual information than newspapers and television news coverage (Neuman et al., 1992). Oftentimes, news magazines can compress, elaborate upon and critique their daily counterparts (Griffin, 2004). Neuman et al. (1992) noted that news magazines contain "more references to expert sources, definitions of terms and concepts, and more analysis of the causes and consequences, and possible policy outcomes" (p. 58). It is these strengths, and their availability to the general public, vast reach and their in-depth coverage on major issues, that make news magazines an appropriate medium for studying the coverage of climate change.

Newsweek. Newsweek circulation is 2,646,613 (Audit Bureau of Circulations, 2009). Newsweek's large circulation makes it an appropriate medium to study because of its vast reach and influence on the general population.

U.S. News and World Report. The circulation is 1,365,652 (Audit Bureau of Circulations, 2009). U.S. News and World Report has been selected because of its circulation and reach within the U.S.

Maclean's. Maclean's is "Canada's only national weekly current affairs magazine" circulation is 355,054 (Audit Bureau of Circulations, 2009). Maclean's prides itself on "strong investigative reporting and exclusive stories from leading journalists in the fields of international affairs, social issues, national politics, business and culture"

The Economist. The Economist circulation of 810,821 for its North American Edition (Audit Bureau of Circulations, 2009) and prides itself on the magazine's "extreme center" political 
position (The Economist, n.d.). Although The Economist has a circulation of only 800,000 in the U.S., it is distributed in over 200 countries, selling over 1 million copies each week (Worldwide circulation, 2008)

\section{Method}

This study focuses on the dominant frames used in the reporting of climate change between 1989 and 2009, any change in frames, and by which publication. A total of 476 news articles was analyzed, all of the articles dealing with climate change in four publications, Newsweek, U.S. News and World Report, (both American news magazines) Maclean's (Canadian), and The Economist (United Kingdom) in six calendar years four years apart, 1989, 1993, 1997, 2001, 2005 and 2009.

Each article was coded for frames, tone of the article, and how the science was framed. The articles were identified through a Lexis/Nexis search where any of the following terms appeared at least once in the text: climate change, global warming, or greenhouse effect. The latter terms was once the most commonly accepted term used in media discourse to describe what now most commonly is referred to as climate change (Carvalho, 2005).

Twelve of 15 frames examined were previously studied ( Boykoff (2008b) and the other three were identified during a pre-test for this analysis. The frames were grouped in these five categories:

(1) political-economic. This was the largest frame, accounting for 274 articles (57.6\%) articles. This frame consisted of three subcategories: political, economic, and business.

(2) culture and society. This was the second most predominant frame, appearing in 80 $(16.8 \%)$ articles. The six sub-frames were: popular culture, justice and risk, transport, public understanding, religion, and stewardship.

(3) scientific. This frame dominated 73 of the articles (15.3\%). It included discovery, applied science, and funding.

(4) Ecological/Meteorological. It accounted for 42 articles (8.8\%) articles containing these categories: weather and biodiversity. 
The fifth frame category, general or other, contained only seven articles and was therefore excluded from discussion or analysis.

Articles were also classified as (1) episodic, often in event-oriented style, taking the form of a case study, focusing now rather than on background or context, or (2) thematic, articles more abstract, focusing on outcomes and solutions, typically with background information. (Iyengar, 1991). A second coder analyzed 10 percent of the articles and inter-coder reliability on 25 variables ranged from .80 to 100 percent.

\section{Results}

This longitudinal study of magazine news coverage of a major controversial issue, climate change, focused on three questions: (1) how was the issue framed?; (2) did the frames change over time?; and (3) were the frames consistent across magazines?

The term "greenhouse effect," a major descriptor many years ago, has almost disappeared, as shown in Table 1. By the 1990's, greenhouse effect was being used less and less and by 2000 was virtually gone. Although the term global warming increased over this time period, it has been, of late, matched, if not surpassed by climate change, the preferred scientific term because it is more encompassing (IPCC, 2007). Climate change refers more to change in the climate due to multiple causes, while global warming is more specifically attributed to human influence; it remains a partisan debate (Bolstad, 2007). Today, both climate change and global warming are widely accepted terms but carry very different connotations (Bolstad, 2007). 
Table 1: When Green House Effect Became Global Warming and Climate Change

\begin{tabular}{lrrrrrr} 
& 1989 & 1993 & 1997 & 2001 & 2005 & \multicolumn{1}{c}{2009} \\
Primary Frame & $(\mathrm{n}=117)$ & $(\mathrm{n}=21)$ & $(\mathrm{n}=126)$ & $(\mathrm{n}=154)$ & $(\mathrm{n}=126)$ & $(\mathrm{n}=130)$ \\
Climate Change & $12 \%$ & 43 & $29 \%$ & $32 \%$ & $40 \%$ & $49 \%$ \\
Global Warming & 44 & 43 & 61 & 66 & 59 & 49 \\
Green House Effect & 44 & 14 & 10 & 2 & 1 & 2 \\
$\quad \mathrm{X}^{2}(15, \mathrm{~N}=484)=48.4, \mathrm{p}=.001$ & & & & & &
\end{tabular}

The frames used to describe climate change did change over the 20-year period (see Table 2), and while the four publications also changed, their use of frames was consistent. Although the political-economic set of frames dominated each year of the six-year study, it increased in usage in the 1990s as did the culture and society of frames. As Table 2 indicates, their increase came at the loss of scientific and ecological/meteorological frames. As Table 3 shows, the four magazines were almost identical.

Table 2: Frames Used by Four Magazines to Describe Climate Change over 20 years

$\begin{array}{lcccccc} & 1989 & 1993 & 1997 & 2001 & 2005 & 2009 \\ \text { Primary France } & (n=72) & (n=26) & (n=92) & (n=131) & (n=78) & (n=70) \\ \text { Ecological/Meterological } & 15 \% & 15 \% & 10 \% & 8 \% & 9 \% & 1 \% \\ \text { Political-Economic } & 46 & 46 & 57 & 65 & 65 & 57 \\ \text { Culture and society } & 13 & 16 & 20 & 18 & 12 & 25 \\ \text { Scientific } & 26 & 23 & 13 & 10 & 14 & 17 \\ X^{2}(15, N=469)=27.885, p=.022 & & & & & \end{array}$

Table 3: Frames Used by Each of the Four Magazines to Describe Climate Change, 19892009.

$\begin{array}{lcccc}\text { Primary Frame } & \begin{array}{c}\text { Mcleans } \\ (\mathrm{n}=79)\end{array} & \begin{array}{c}\text { Newsweek } \\ (\mathrm{n}=134)\end{array} & \begin{array}{c}\text { Economist } \\ (\mathrm{n}=178)\end{array} & \begin{array}{c}\text { U.S. News } \\ (\mathrm{n}=78)\end{array} \\ \text { Ecological/Meteorological } & 10 \% & 12 \% & 6 \% & 10 \% \\ \text { Political-Economic } & 56 & 55 & 61 & 62 \\ \text { Culture and Society } & 19 & 17 & 17 & 14 \\ \text { Scientific } & 15 & 16 & 16 & 14 \\ X^{2}(9, \mathrm{~N}=469)=5.197, \mathrm{p}=.817 & & & & \end{array}$


The four magazines also were similar in how they depicted climate change as either episodic or thematic, but again their use also changed over time. Table 4 demonstrates a significant change, a graduate shift from episodic to thematic.

Table 4: Episodic versus Thematic Frames

$\begin{array}{lcccccc} & 1989 & 1993 & 1997 & 2001 & 2005 & 2009 \\ \text { Primary Frame } & (\mathrm{n}=117) & (\mathrm{n}=21) & (\mathrm{n}=126) & (\mathrm{n}=154) & (\mathrm{n}=126) & (\mathrm{n}=130) \\ \text { Episodic } & 53 \% & 42 \% & 43 \% & 33 \% & 41 \% & 24 \% \\ \text { Thematic } & 47 & 58 & 57 & 67 & 59 & 76 \\ \mathrm{X}^{2}(5, \mathrm{~N}=476)=15.115, \mathrm{p}=.01 & & & & & & \end{array}$

\section{Discussion}

This study examined the frames used to portray climate change in Maclean's, Newsweek, The Economist, and U.S. News and World Report from 1989 to 2009. Examining the frames used to portray climate change demonstrated that climate change has continually been framed in news magazines as a major political issue and increasingly as a social and cultural issue as well.

The study revealed that there were no major differences in the way that climate change was framed between publications. However, the frames that were used to portray the issue over time did change.

The major primary frame that emerged from this study was that of political-economic. The study also showed a significant shift from the scientific frame as the second most represented frame to the social and cultural frame. This shift indicates that the issue has become more commonplace in the lives of everyday citizens. Rather than view the issue as a scientific issue that citizens have no control over or effect upon, the social cultural frame encompasses issues of stewardship, pop culture, public understanding, and justice and risk.

Global warming, overall, was the most frequently used term to describe the climate change phenomenon, appearing 814 times, followed by climate change, appearing 530 times. The term greenhouse effect only appeared 121 times during the study. This was consistent with the reasoning of Bolstad (2007) who noted that both terms are widely accepted. It is 
important to remember that both terms carry very different connotations (Bolstad, 2007). The consistency of the term global warming as found in this study may be attributed to the idea that many Democrats continue to use the term because of its connotations, with global warming reinforcing the human factor in contributing to climate change (Bolstad, 2007). Bolstad also noted that the Republican Party began to coin the term climate change as part of a political move to dominate debates on environmental issues. This move was evident in the data as a statistically significant shift from the terminology used before that date.

The findings were also consistent with those of Carvalho (2005), who noted that after 1988 the term greenhouse effect began to slip from the media landscape. It was replaced by global warming, which was the most popular term in 1990 (Carvalho, 2005). The findings in this study confirmed this, in that global warming was the most commonly used term in 1989, appearing 109 times. Greenhouse effect and climate change appeared 89 and 17 times respectively.

Many studies have found coverage of climate change to be episodic rather than thematic (Boykoff \& Boykoff, 2007; Check, 1995; Hutchison, 2008; Nitz \& Ihlen, 2006; von Storch \& Krauss 2005). However, this study indicated a significant increase in the number of thematic stories about climate change. The differences may be attributed to the difference in medium, as this is one of the first studies to look at the issue as covered by news magazines.

Although many previous studies have found that coverage on science-related topics increased surrounding major news events such as conferences or the passage of legislation (Nisbet \& Lewenstein, 2002), this study was not able to track such changes, as each article was coded by year, rather than specific date. However, qualitatively the results were partially supported. Many articles would begin with the happenings of a major event, but differed in that they proceeded to give much interpretation and background information on the topic. This finding is important as Corbett and Durfee (2004) noted that providing such context leads to higher levels of certainty and understanding.

Nisbet and Lewenstein (2002) noted that the use of credible sources, mainly government agencies and scientists who are considered credible and necessary to scientific matters, will increase the credibility of a news story. These findings were partially supported by this 
study. This study found that while "other" was the most common category for sources, appearing 215 times, educational institutions were credited with providing information 178 times, government agencies 86 times, and appointed government officials 81 times. The category other consisted of a gamut of sources, including business people, independent citizens, former officials, and the like.

Conversely, it was also found that special interest groups, non-government organizations (NGO), and independent research organizations were coded as providing source information 177 times. Qualitatively, it was also noted that information was often provided without any sourcing. Furthermore, when sources are provided it is often difficult for the reader to know what type of source an organization might be, such as a "research organization" that is possibly funded by an oil producers association.

This study contributed to the existing literature in three ways. First, it was one of the first studies to look at how climate change has been framed in news magazines. Existing research had primarily focused on newspaper and broadcast coverage of the topic. A study of news magazines, however, is also important because of their reach throughout the general populace. Second, this is one of the only studies to look at the framing of climate change over a 20-year time period. Many of the existing studies focus on a time period of one to three years. The longer time period allows for the identification of trends, whereas a shorter study gives more of a snapshot of the current state of affairs. Finally, this study looked at not only American news magazines but also one Canadian magazine and one British magazine. This identified differences in the way that climate change is portrayed to different populations throughout the world.

Furthermore, this study identified a new category for framing the science as neutral. This category was prevalent throughout the sample, including text that asserted climate change as fact, yet did not include any scientific studies to support the assertion.

Limitations of the study include its inability to weight articles according to the amount of information that was present regarding climate change. Because all articles with at least one sentence dedicated to climate change were included in the sample, an article that only had 
one sentence concerning climate change was given the same weight as one that contained several paragraphs.

The implications of the study are numerous. First, it is clear that the most common frame used for portraying climate change is the political-economic frame. The implications are that climate change is a problem that should be left to governments to solve, whether that is through treaties, regulations, or political agreements. By using this frame, the message is sent that it is not up to individuals or businesses to take responsibility unless some regulation exists.

A second implication with regard to the science is that before 2002 the science was largely portrayed as ambiguous, whereas after that year it was largely portrayed as either valid or neutral. The implications of these frames indicate a societal acceptance of climate change as a global and political issue.

But the most important implication of this study is that it reaffirms the idea that what is important about things we describe as facts change when they become "news," often described in words and images linked to the consumer's reference points in order to guide the consumer to a source-desired action. In other words, news is like truth, and like beauty. It is in the eye of the beholder. But just as importantly, and more ominously, shaped by originator.

The media play a crucial role in reinforcing verbiage as it relates to a problem or an issue. Carvalho (2005) noted that "the media are a crucial site for the definition and re-definition of meanings associated with climate change" (p. 2). The ability of the public to understand environmental issues depends largely upon how such issues are constricted by media verbiage, and without public understanding there can be no public debate or resolution (Carvalho, 2005).

Coverage on climate change has ebbed and flowed over time, peaking in the late eighties and again in the late nineties (Carvalho, 2005). Boykoff (2007a) found that newspaper coverage of climate change in U.S. prestige-press had recently increased by about two and a half times between 2003 and 2006. Boykoff (2008a) found that network television evening news 
coverage of climate change increased from less than 10 news segments in 1995 to over 20 in 2004, with a spike of over 40 segments in 1997.

\section{Objective Reporting}

The attempt to provide balance and objectivity to a story is a long-standing tradition in journalism. Gamson and Modigliani (1989) stated, "In news accounts, interpretation is generally provided through quotations, and balance is provided by quoting spokespersons with competing views" (p. 8). The "journalistic norm" of fair and balanced reporting seems to hold especially true in the reporting of science and climate change.

It has been common practice for journalists to provide "balanced" coverage of climate change; despite a general scientific consensus stating that climate change is happening (Antilla, 2005; Boykoff \& Boykoff, 2007; Smith, 2005). The attempt to provide a balanced report often leads to the introduction of even more bias, with the claims of special interest groups being validated through news coverage (Antilla, 2005).

In the case of global climate change, introducing dissent is largely problematic, especially when the scientific community agrees (Corbett \& Durfee, 2004). Special interest groups that have also been referred to as "climate contrarians" are responsible for introducing much of the dissent in the debate over climate change (Boykoff, 2007b). The climate contrarians are known for spouting "ignorance claims" (Holstein \& Stocking, 2006) and adhering to strict rhetoric to get their message out through the media (Boykoff, 2007b).

A study by Foust and O'Shannon Murphy (2009) supported these findings. They found that the apocalyptic framing of climate change opened the findings of the scientific community to objection and pointed to environmentalists as scaremongers. This frame also removes the responsibility for global warming from humans, blaming it on fate instead (Foust \& O’Shannon Murphy, 2009).

A study by Holstein and Stocking (2006) on environmental concerns surrounding the hog industry found that the treatment of opposing claims depended largely on journalists' perceptions of their own role. Some journalists in the study said their role as a journalist depended on a number of factors, including their understanding of science and perceptions of 
their audience. In some cases, journalists felt it was fair to make their own assessment of the validity of scientific studies, while in other cases journalists refrained from making assessments and simply presented the facts for both sides of the story.

Yet recently Boykoff (2007a) noted that stories depicting anthropologic contributions as the main source of climate change increased by over 30\% between 2003 and 2006 . Whereas balanced accounts accounted for $37 \%$ of the newspaper articles related to climate change in 2006 , they were present in only $3 \%$ of stories in 2003. Furthermore, in an examination of both mainstream and alternative news sources, Kenix (2008) found that very little of the climate change coverage portrayed the issue as a topic still up for debate. Only $14 \%$ of the articles examined for both mediums mentioned any debate about the causes of climate change (Kenix, 2008).

\section{Episodic vs. Thematic}

Despite its growing prevalence in mainstream media, recent studies have found that coverage related to climate change has been episodic in nature (Boykoff \& Boykoff, 2007; Check, 1995; Hutchison, 2008; Nitz \& Ihlen, 2006; von Storch \& Krauss, 2005). Episodic, as opposed to thematic framing, covers issues in relation to certain events. Iyengar (1991) stated: The episodic news frame takes the form of a case study or event-oriented report and depicts public issues in terms of concrete instances. The thematic frame, by contrast, places public issues in some more general or abstract context and takes the form of a "takeout" or "backgrounder," report directed at general outcomes or conditions. (p. 14)

Episodic coverage does not allow for the same type of interpretation as that of thematic coverage. Taking into account the complexities of climate change, episodic coverage oftentimes does not provide a complete picture of the issue (Boykoff, 2007b; Boykoff \& Boykoff, 2007). In the case of climate change, this creates a problem of consistency and context.

Because of its episodic nature, coverage of climate change has thus ebbed and flowed over time (Boykoff, 2007b). Peaks in coverage have been attributed to key events surrounding the topic. These events include the release of Al Gore's documentary An Inconvenient Truth and media attention on the Twelfth Conference of the Parties to the United Nations Framework 
Convention on Climate Change (Boykoff, 2007b). Event-related reporting was visible in coverage of the biotechnology debate in Switzerland. Nisbet and Lewenstein (2002) found that coverage on biotechnology peaked in the time surrounding major conferences, Congressional hearings and related legislation, breakthroughs in technology and growth of stock.

Coverage of politics on European television has also been found to be episodic rather than thematic in nature, focusing on events within the past 24 hours (Semetko \& Valkenburg, 2000). This type of episodic coverage lacked in both context and interpretation, therefore discouraging further analysis of why the event occurred (Check, 1995). Furthermore, issues that are reported as episodic are in danger of going unreported for long periods of time, until another event brings the issue back into the media (Nisbet \& Lewenstein, 2002).

In order to understand climate change, context must be provided. Corbett and Durfee (2004) found that providing context to a story about climate change led to higher levels of certainty about climate change; the reverse was true when context was not provided. Results fell in the middle in cases where context and controversy were provided throughout the story. Furthermore, episodic coverage does not allow for audiences to see the entire picture. Iyengar (1991) posited that episodic coverage might be one reason why Americans cannot see interconnections on various issues in the media. The risk of episodic coverage is that many issues of significance may not be included in news coverage; therefore citizens cannot critically observe national affairs (Iyengar, 1991).

Episodic coverage can also affect policy decisions and the decision-making process. Nitz and Ihlen (2006) noted that "episodic coverage makes it more difficult for policy-makers and stakeholders to come together to make decisions on complex environmental issues" (p. 21). A study released by the Pew Research Center for the People and the Press found that whereas in April 2008, 71\% of people surveyed believed that there was "solid evidence that the earth is warming," that number fell to 57\% in October 2009 ("Pew Research Center for the People and the Press," 2009).

The same study found that $50 \%$ of the people surveyed favor putting limits on carbon dioxide emissions and making companies pay for their emissions, while 36\% oppose the idea (Pew 
Research Center for the People and the Press, 2009). The results indicate a clear split on opinion related to the importance of and policy issues having to do with climate change despite a scientific consensus.

Sources used in the reporting of climate change are also an important factor in determining credibility of information about climate change. Nisbet and Lewenstein (2002) stated that "government agencies and scientists are widely considered credible and necessary authorities in matters of scientific and environmental uncertainty" (p. 386). When the quoted sources are more credible, the story and topic become more credible.

\section{Framing Effects}

Research on the frames used to report climate change has provided conflicting results. One of the more common frames used for portraying climate change in the media has been that of contention (Antilla, 2005; Boykoff, 2007b; Nitz \& Ihlen, 2006). Boykoff (2007b) supported this and noted that the framing of climate change has been that of "conflict and contentions" despite the scientific consensus surrounding climate change. These findings were supported by Hart (2008) in a study of CNN and Fox News broadcasts, with the most common frame being that of scientific uncertainty on both CNN and Fox. Antilla (2005) found numerous examples of articles framed as valid science. However, debate controversy and uncertainty were also well represented in the sample.

It is clear that the ways in which science is reported can cause confusion. A lack of general scientific knowledge, by both the reporter and audiences, causes the reporter to make an even greater effort to be fair and balanced. Boykoff (2007b) noted, "Through framingconstructed through processes of power and scale - media coverage of anthropologic climate change can depict an arena of great confusion and intense conflict rather than scientific consensus" (p. 478).

Also, the repetition of certain fames throughout a news story or series of stories keeps that frame in the minds of the public and legislators. In an examination of dominant frames used in the Columbine tragedy, it was found that frames that were repeated often in news storieslike gun control-were given greater authority and were therefore on the forefront of new legislation (Graber, 2002). 
Frames often affect blame and assignment of responsibility on a number of topics. Iyengar (1989) stated that "the manner in which the news media frame national issues powerfully affects beliefs about cause and treatment" (p. 897). In fact, frames have been said to have more powerful effects than that of persuasion or call to action (McQuail, 2005). Sheufele (2000) said that "framing influences how audiences think about issues" (p. 309).

Framing has the power to affect overall public opinion. First, news coverage has the ability to highlight and bring forth certain issues onto the public agenda. Next, the framing of those objects has the ability to impact "the pictures of those objects in our heads" (McCombs, 1997, p. 48). Both aspects of framing have the power to impact attitudes, opinions and public behavior (McCombs, 1997).

The frames used to cover climate change are important because of the possible effect these frames may have on public discourse. Nitz and Ihlen (2006) noted that "frames are potentially very powerful in impacting both portrayal and understanding of environmental issues" (p. 19). The authors also noted that a lack of media coverage on a particular issue might make it difficult for policymakers to communicate with the public. This is an important concept to consider as public opinion will be affected by political and media frames. Entman (2004) concluded that "public opinion cannot be divorced from the political discourse and media frames that surround it” (p. 142).

This paper will work from the IPCC's definition of any changes to the climate without concern for the specific cause. The IPCC (2007) noted:

Climate change in IPCC usage refers to a change in the state of the climate that can be identified (e.g. using statistical tests) by changes in the mean and/or variability of its properties, and that persists for an extended period, typically decades or longer. It refers to any change in climate over time, whether due to natural variability or as a result of human activity. (p. 30)

This definition allows for a broad exploration of climate change as it is portrayed in the media. For the purposes of this study, the term "climate change" will be used primarily as it has become commonly accepted and encompasses a larger range of issues related to the 
climate than the terms "global warming" or "greenhouse effect." Global warming refers more specifically to the warming of the Earth's surface (Intergovernmental Panel on Climate Change, 2007).

In addition, the articles were coded for the way in which the validity of the science of climate change was framed, using the following definitions (Antilla, 2005): (1) valid science: articles without skepticism, often with authors of scientific research as sources; (2) neutral: not portraying climate research as contentious, uncertain or ambiguous; (3) ambiguous, those de-emphasizing or obscuring scientific findings, and (4) uncertain science, balanced coverage (Boykoff and Boykoff, 2007) introducing balance, and therefore bias, including scientific findings but a lack of consensus in the scientific community, and (5) controversial, articles focusing on climate skeptics usually those with ties to the fossil fuel industry.

Of the three subcategories in the political-economic frame, political was the most predominant, accounting for 232 articles (48.7\%), followed by business, accounting for 29 articles $(6.1 \%)$, and finally the economic, accounting for 13 articles $(2.7 \%)$ of the entire population. Political articles focused primarily on possible legislation to regulate climate change and governments taking responsibility for emissions. Many of the articles were concerned with the ratification of the Kyoto protocol and its related issues. Another major topic that was included under the political frame was the nuclear debate; this frame often discussed United States efforts to move away from carbon emissions or the politics

The culture and society frame consisted of six subcategories, including popular culture, justice and risk, transport, public understanding, religion, and stewardship. The largest subcategory was that of justice and risk, accounting for 32 of the articles (6.7\%). Articles falling under the justice and risk category were likely to discuss the effect of climate change on different populations throughout the world. Other articles within the category covered the health hazards of climate change upon the human race or certain populations of the human race.

Just as individual readers, listeners and viewers utilize frames to place information in context, so also do sources use frames to make some information more salient (and other information less important) thereby creating a specific image to be conveyed to the consumer. Different 
types of sources frame information differently, or at least disseminate information that is framed differently, as indicated by the statistically significant differences in framing of the global warming/climate change issue shown in Table 5.

Table 5: Which Frames Are Used by Which Sources?

\begin{tabular}{|c|c|c|c|c|}
\hline & & Sources & & \\
\hline & Government & Special & Educational & Other \\
\hline & & Interests & Institutions & \\
\hline Frame & $(\mathrm{n}=155)$ & $(\mathrm{n}=94)$ & $(n=60)$ & $(\mathrm{n}=131)$ \\
\hline Ecological/Meteorological & $12 \%$ & $8 \%$ & $15 \%$ & $8 \%$ \\
\hline Political-Economic & 70 & 60 & 22 & 52 \\
\hline Culture and Society & 8 & 12 & 20 & 22 \\
\hline Scientific & 10 & 20 & 43 & 18 \\
\hline
\end{tabular}

Not only is it interesting to study the differences in framing by sources but also the relative amount of framing. Government (including the president, appointed and elected officials as well as government agencies) constitute $35.2 \%$ of all sources and use the political-economic frame by nearly a three-to-one ratio over the other three frames combined. It is noteworthy that government spokespeople are the least likely to discuss the issue in scientific terms.

It might be considered somewhat surprising that individual source types did not differ significantly over time nor by publication as questions in RQ2. The largest percentage of 489 uses of one or more frames was the other category with $30 \%$. Other sources by percentage of frames was special interests, $20 \%$; educational institutions 13\%; government agencies and appointed officials, $10 \%$ each; and in a three-way tie at $6 \%$ each were elected officials, the United Nations, and the president.

The answer to the RQ3 wonder about whether frames were structured in episodic or thematic fashion was partially answered. The appearance of thematic or episodic frames did change significantly by year but not by publication or source. Although $62 \%$ of all frames were 
thematic, it was not always thus. As Table 6 indicates, thematic frames gradually became more dominant over time, although 2005 interrupts a clear-cut upward trend.

\begin{tabular}{|c|c|c|c|c|c|c|}
\hline Episodic & $53 \%$ & $42 \%$ & & & $33 \%$ & $41 \%$ \\
\hline Thematic & 47 & 58 & 57 & 67 & 59 & 76 \\
\hline
\end{tabular}

Table 7: Over-time Use of Terminology of Environmental Change

Percentage of occurrence in news articles

$\begin{array}{llllll}1989 & 1993 & 1997 & 2001 & 2005 & 2009 \\ (n=72) & (n=26) & (n=92) & (n=131) & (n=78) & (n=70)\end{array}$

$\begin{array}{lrrrrrc}\text { Climate change } & 18.4 & 34.6 & 38.3 & 38.2 & 63.3 & 91.4 \\ \text { Global } & 68.4 & 73.1 & 81.0 & 77.9 & 90.9 & 92.8 \\ \text { Greenhouse } & 67 / 1 & 11.5 & 13 / 8 & 1 / 5 & 1.3 & 2.9\end{array}$

Means occurrences

$\begin{array}{lrrrrrr}\text { Climate Change } & .22 & .35 & .79 & .82 & 1.57 & 2.83 \\ \text { Global Warming } & 1.43 & 1.50 & 1.87 & 1.48 & 1.77 & 2.26 \\ \text { Greenhouse Effect } & 1.17 & .12 & .20 & .05 & .01 & .05\end{array}$

The respective Fs and p values are: 20.851, 1.919, 33.246, .001, .09, and .001

In addition to source framing of sources, the question of how the four publications used frames in depicting the issue, that is as valid science, neutral, or as uncertain science, that is with ambiguous cause and effects. 
Table 8: Overall Depiction of Climate Warming in Four Magazines Over Time

$\begin{array}{llllll}1989 & 1993 & 1997 & 2001 & 2005 & 2009 \\ (n=72) & (n=26) & (n=92) & (n=131) & (n=78) & (n=70)\end{array}$

$\begin{array}{lllllll}\text { Valid Science } & 18 \% & 16 \% & 18 \% & 22 \% & 59 \% & 59 \% \\ \text { Neutral } & 38 & 42 & 50 & 66 & 28 & 26 \\ \text { Uncertain/Ambiguous } & 44 & 42 & 32 & 12 & 21 & 15 \\ & & & & & & \\ \mathrm{X}^{2}(10, \mathrm{~N}=476)=95.734, \mathrm{p}=.001 & \end{array}$

In other words, it was not until about 2005 that these publications even considered the question as answered. In fact, from the beginning until 2001, the journalistic requirement of objectivity, of finding an opposing opinion for every view, was still being practice.

There was no significant difference among the publications in regard to how the subject was treated.

Prior to 1988 the term 'greenhouse effect' was referenced almost exclusively in discourse on climate change (Carvahlo, 2005). However, 'global warming' gained popularity and by 1990 was the most commonly used term for climate change in the news media (Carvahlo, 2005). In 2002, the Republican Party began to coin the term climate change as part of a political move to dominate debates on environmental issues (Bolstad, 2007). Since then, climate change has become the preferred scientific term because it is more encompassing (Intergovernmental Panel on Climate Change, 2007). Climate change refers more to change in the climate due to multiple causes, while global warming is more specifically attributed to human influence; it remains a partisan debate (Bolstad, 2007). Today, both climate change and global warming are widely accepted terms but carry very different connotations (Bolstad, 2007). Many Democrats continue to use the term global warming (Bolstad, 2007). The use of one term or another indicates a preference of the sender in how they view the topic or want the receiver to view the topic, thus framing it through verbiage. 
The findings of this study confirm that verbiage continues to be an important part of the framing process. As noted by Entman (1993), straying from these commonly accepted terms would result in a loss of credibility and meaning.

Verbiage is an important part of the framing process. Once certain terms become accepted, the language itself has power over audience interpretations. The use of "certain words or phrases" (McQuail, 2005, p. 378) can be used to convey specific meanings. Verbiage is so integral to framing that straying from commonly accepted terms might result in a loss of understanding (Entman, 1993). It is evident from the results of this study that although the terms used to describe climate change have evolved over time, there still exists an importance and meaning that is attached to the terms themselves.

Boykoff (2007a) noted that newspaper coverage of climate change in the U.S. prestige-press had recently increased by about two-and-a-half times between 2003 and 2006. This study revealed a trend towards an increase in coverage from 1989 to 2009. With the exception of 1993, articles related to climate change increased from 75 articles in 1989, 25 articles in 1993, 93 articles in 1997, and 130 articles in 2005, to 148 articles in 2009. These numbers indicate that climate change is becoming an increasingly important topic in the news media. However, it is difficult to confirm an upward trend because samples were taken at four-year increments rather than consistently over the 20 -year period.

This study saw an increase in articles framed as uncertain science, which accounted for seven articles (5\%) in 2001 to 10 articles (14.3\%) in 2009. These findings were inconsistent with the findings of Boykoff (2007a), which noted that balanced accounts decreased from $37 \%$ of articles to $3 \%$ of articles from 2003 to 2006 . Yet the study yielded similar results to those of Kenix (2008), who also found that only $14 \%$ of the articles examined in mainstream and alternative news sources mentioned any debate about the causes of climate change.

However, the study also found a sizeable increase in the amount of valid science articles from 14 articles (18.4\%) to 41 articles $(58.6 \%)$ between 1989 and 2009. These results were similar to the results of Boykoff (2007a), which noted that stories depicting anthropologic contributions as the main source of climate change increased by over $30 \%$ between 2003 and 2006. This study found an increase from $22.1 \%$ in 2001 to $58.6 \%$ in 2009 . Results were also 
similar to those of Antilla (2005), who found numerous examples of articles framed as valid science. However, debate controversy and uncertainty were also well represented in the sample.

These differences may be attributed to differences in medium. Whereas news magazines have the ability to give more in-depth coverage on an issue, providing interpretation for the reader, newspapers do not have this luxury. Newspapers are more inclined to quote both sides of the story to provide interpretation (Gamson \& Modigliani, 1989). Although not all agree as to likely effects of global warming, most scientists agree that it is occurring. The Nationals Aeronautics and Space Administration notes that carbon dioxide is now higher, some 390 parts per million, than it has been in more than 800 thousand years (Climate Change, 2010) and the Pew Center for of Global Climate Change suggests that without changes, the earth's temperature could rise by 10 degrees Fahrenheit by the end of this century (climateactionreserve.org, 2010). Underlying this lack of agreement are various political, economic and social concerns, all of which are based on differences of opinions as to causes, solutions -- even as to whether it is occurring. The vested interests of particular groups lead to different interpretations and often intentional different presentations to the final decision-maker, the public. The public ultimately will determine what actions are to be taken, if any, based on public understanding of the topic. Much of that understanding will be based on how the issue is presented. In other words, what aspects are included and emphasized and what are left out. In other words, how it is framed for the audience. 


\section{References}

Antilla, L. (2005). Climate of skepticism[sic]: U.S. newspaper coverage of the science of climate change. Global Environmental Change Part A, 15(4), 338-352. doi: 10.1016/j.gloenvcha.2005.08.003 Retrieved April 3, 2009, from http://www.sciencedirect.com/science/article/B6VFV-4HJC4JY2/2/e0ecf7915f6694f5e8bb18f334389a44

Audit Bureau of Circulations: ECerc (June 30, 2009). Retrieved November 17, 2009, from http://www.accessabc.com/products/freereports.htm

Berinsky, A. J., \& Kinder, D. R. (2006). Making sense of issues through media frames: Understanding the Kosovo crisis. Journal of Politics, 68(3), 640-656. doi:10.1111/j.1468-2508.2006.00451.x Retrieved August 21, 2009, from http://libaccess.sjlibrary.org/login?url=http://search.ebscohost.com/login.aspx?direct $=$ true $\& \mathrm{db}=\mathrm{aph} \& \mathrm{AN}=21437040 \&$ site $=$ ehost-live

Bolstad, E. (December 7, 2007). "Climate change" or "global warming." Retrieved November 15, 2009, from http://www.mcclatchydc.com/231/story/22730.html

Boykoff, M. T. (2007a). Flogging a dead norm? Newspaper coverage of anthropogenic climate change in the United States and United Kingdom from 2003 to 2006. Area, 39(4), 470-481. Retrieved April 5, 2009, from http://libaccess.sjlibrary.org/login?url=http://search.ebscohost.com/login.aspx?direct $=$ true $\& \mathrm{db}=\mathrm{s} 3 \mathrm{~h} \& \mathrm{AN}=27524908 \&$ site $=$ ehost-live

Boykoff, M. T. (2007b). From convergence to contention: United States mass media representations of anthropogenic climate change science. Transactions of the Institute of British Geographers, 32(4), 477-489. doi:10.1111/j.14755661.2007.00270.x Retrieved April 5, 2009 from http://libaccess.sjlibrary.org /login?url=http://search.ebscohost.com/login.aspx?direct=true \&db=aph\&AN=27091 $875 \&$ site $=$ ehost-live

Boykoff, M. T. (2008a, January). Lost in translation? United States television news coverage of anthropogenic climate change, 1995-2004. Climatic Change, 86(1-2), 1-11. doi: 10.1007/s 10584-007-9299-3 Retrieved November 15, 2009, from http://www.springerlink.com/content/74338023j82k2873/

Boykoff, M. T. (2008b). The cultural politics of climate change discourse in UK tabloids. Political Geography, 27(5), 549-569. doi: 10.1016/j.polgeo.2008.05.002 Retrieved 
September 21, 2009 from http://www.sciencedirect.com /science/article/B6VG2-4SWG0D9-2/2/cf7fb485e95f804ec45cbf148e135af7

Boykoff, M. T., \& Boykoff, J. M. (2007). Climate change and journalistic norms: A casestudy of U.S. mass-media coverage. Geoforum, 38(6), 1190-1204. doi: 10.1016/j.geoforum.2007.01.008 Retrieved April 3, 2009, from http://www.sciencedirect.com/science/article/B6V68-4NC5T4P1/2/b12f785007ccfc1f461e327fa34af11c

Carvalho, A. \& Peterson, T. R. (2009). Discursive constructions of climate change: Practices of encoding and decoding. Environmental Communication, 3(2), 131-133. doi:10.1080/17524030902935434 Retrieved November 17, 2009 from http://search.ebscohost.com/login.aspx?direct=true \&db=ufh\&AN=41539621\&login page $=$ Login. asp\&site $=$ ehost-live

Carvalho, A. (2005). Representing the politics of the greenhouse effect: Critical Discourse Studies, 2(1), 1-29. doi:10.1080/17405900500052143 Retrieved April 6, 2009, from http://search.ebscohost.com/login.aspx?direct=true\&db=ufh\&AN= 16669761\&loginpage=Login. asp \&site=ehost-live

Check, T. (1995). The evaluation of scientific evidence on the Exxon Valdez oil spill. Conference Proceedings-National Communication Association/American Forensic Association (Alta Conference on Argumentation, 397-402. Retrieved April 6, 2009, from http://search.ebscohost.com/login.aspx?direct=true \&db=ufh\&AN= 20755204\&loginpage $=$ Login. asp \&site=ehost-live

Climate Change (2010). Retrieved October, 2010 from http://climate.nasa.gov/

Corbett, J. B., \& Durfee, J. L. (2004). Testing public (un)certainty of science-media representations of global warming. Science Communication, 26(2), 129-151. doi: $10.1177 / 1075547004270234$

Entman, R. M. (1993). Framing: Toward clarification of a fractured paradigm. Journal of Communication, 43(4), 51-58. doi: 10.1111/j.1460-2466.1993.tb01304.x

Entman, R. M. (2004). Projections of power: Framing news, public opinion, and U.S. foreign policy. Chicago, IL: The University of Chicago Press. .

Foust, Christina R., \& O’Shannon Murphy, William (2009). Revealing and reframing apocalyptic tragedy in global warming discourse. Environmental Communication, 3(2), 151-167. doi:10.1080/17524030902916624 Retrieved September 21, 2009, 
from http://search.ebscohost.com/login.aspx?direct=true \&db=ufh\&AN=41539619 \&loginpage $=$ Login. asp $\&$ site $=$ ehost-live

Gamson, W. A., \& Modigliani, A. (1989). Media discourse and public opinion on nuclear power: A constructionist approach. American Journal of Sociology, 95(1), 1-37. Retrieved April 21, 2009, from http://www.jstor.org/stable/2780405

Graber, Doris A. (2002). Mass media and American politics (Sixth Edition). Washington, D.C.: CQ Press.

Griffin, M. (2004). Picturing America's “war on terrorism” in Afghanistan and Iraq. Journalism, 5(4), 381-402. doi:10.1177/1464884904044201 Retrieved November 17, 2009, from http://search.ebscohost.com/login.aspx?direct=true \&db $=$ ufh \&AN=15273489\&loginpage $=$ Login.asp\&site=ehost-live

Hart, Philip (2008). Market influences on climate change frames in CNN and Fox news channel broadcasts. Conference Papers-International Communication Association, 1-38. Retrieved April 6, 2009, from http://search.ebscohost.com/login . aspx $?$ direct=true $\& d b=u f h \& A N=36956440 \&$ loginpage $=$ Login. asp $\&$ site $=$ ehost-live

History of Newsweek. (2007). Retrieved November 14, 2009, from http://www.newsweek.com/id/42663

Holstein, Lisa, \& Stocking, Holly S. (2006). Manufacturing doubt: Journalists' roles and the construction of ignorance in a scientific controversy. Conference PapersInternational Communication Association, 1-34. Retrieved April 6, 2009, from http://search.ebscohost.com/login.aspx?direct=true \&db=ufh\&AN=27204309\&login page $=$ Login. asp \&site $=$ ehost-live

Hutchison, P. J. (2008). Journalism and the perfect heat wave: Assessing the reportage of North America's worst heat wave, July-August 1936. American Journalism, 25(1), 31-54. Retrieved April 6, 2009, from http://search.ebscohost.com/login.aspx?direct=true \&db=ufh\&AN=32066667\&login page $=$ Login. asp $\&$ site $=$ ehost-live

Intergovernmental Panel on Climate Change (2007, November). Climate Change 2007: Synthesis Report. Valencia, Spain.

Iyengar, S. (1989). How citizens think about national issues: A matter of responsibility. American Journal of Political Science, 33(4), 878. Retrieved April 6, 2009, from http://search.ebscohost.com/login.aspx?direct=true \&db=bth $\& \mathrm{AN}=5243188 \&$ loginpage $=$ Login. asp \&site=ehost-live 
Iyengar, S. (1991). Is anyone responsible? How television frames political issues. Chicago, IL: The University of Chicago Press.

Kenix, L. J. (2008). A comparative analysis of climate change in the alternative and mainstream press of New Zealand and the United States. Conference PapersInternational Communication Association, 1-31. Retrieved April 3, 2009, from http://search.ebscohost.com/login.aspx?direct=true \&db=ufh\&AN=36956799\&login page $=$ Login $\cdot$ asp $\&$ site $=$ ehost-live

Maclean's (n.d.). Retrieved November 14, 2009, from http://www.macleans.ca/ about/index.jsp

McCombs, Maxwell (1997). New frontiers in agenda setting: Agendas of attributes and frames. Mass Comm Review, 24(1 and 2), 32-52. Retrieved May 4, 2009, from http://libaccess.sjlibrary.org/login?url=http://search.ebscohost.com/login.aspx?direct $=$ true $\& \mathrm{db}=$ ufh $\& \mathrm{AN}=4510169 \&$ site $=$ ehost-live

McQuail, D.. (2005). McQuail's mass communication theory (Fifth Edition ed.). Thousand Oaks, CA: Sage Publications Inc.

Neuman, W. R., Just, M. R., \& Crigler, A. N. (1992). Common knowledge: News and the construction of political meaning. Chicago, IL: University of Chicago Press.

Nisbet, M. C., \& Lewenstein, B. V. (2002). Biotechnology and the American media: The policy process and the elite press, 1970 to 1999. Science Communication, 23(4), 359. Retrieved April 21, 2009, from http://search.ebscohost.com/login.aspx?direct=true \&db=ufh\&AN=6807153\&loginp age $=$ Login. asp \&site $=$ ehost-live

Nitz, M., \& Ihlen, O.(2006). Oil and gas as natural riches or environmental problems: Framing contests in public relations. Conference Papers-International Communication Association, 1-39. Retrieved April 6, 2009, from http://search.ebscohost.com/login.aspx?direct=true \&db=ufh\&AN=27204402\&login page $=$ Login. asp \&site $=$ ehost-live

Pew Center on Global Climate Change, (2010). Retrieved from http://climateactionreserve.org/resources.climate-change-facts/

Pew Research Center for the People and the Press (2009). Fewer Americans See Solid Evidence of Global Warming. Retrieved November 14, 2009, from http://peoplepress.org/report/556/global-warming 
Scheufele, Dietram A. (2000). Agenda-setting, priming, and framing revisited: Another look at cognitive effects of political communication. Mass Communication \& Society, 3(2\&3), 297-316. Retrieved April 11, 2009, from

http://libaccess.sjlibrary.org/login?url=http://search.ebscohost.com/login.aspx?direct $=$ true $\& \mathrm{db}=\mathrm{ufh} \& \mathrm{AN}=3455306 \&$ site $=$ ehost-live

Semetko, Holli A., \& Valkenburg, Patti M. (2000). Framing European politics: A content analysis of press and television news. Journal of Communication, 50(2), 93.

Retrieved May 4, 2009, from http://search.ebscohost.com/login.aspx ?direct $=$ true $\& \mathrm{db}=\mathrm{ufh} \& \mathrm{AN}=3227833 \&$ loginpage $=$ Login. asp $\&$ site $=$ ehost-live

Smith, J. (2005). Dangerous news: Media decision making about climate change risk. Risk Analysis: An International Journal, 25(6), 1471-1482. Retrieved April 5, 2009, from http://search.ebscohost.com/login.aspx?direct=true\&db=s3h\&AN= 19473332\&loginpage $=$ Login. asp\&site=ehost-live

The Economist (n.d.). Retrieved November 14, 2009, from http://www.economist.com /help/DisplayHelp.cfm?folder=663377\#About_The_Economist

U.S. News history (2007). Retrieved November 14, 2009, from http://www.usnews.com/usnews/usinfo/history.htm

von Storch, H. \& Krauss, W . (2005). Culture contributes to perceptions of climate change. Nieman Reports, 59(4), 99-102. Retrieved April 6, 2009, from http://search.ebscohost.com/login.aspx?direct=true \&db=ufh\&AN=19403355\&login page $=$ Login $\cdot$ asp $\&$ site $=$ ehost-live

Worldwide circulation (2008). Retrieved November 17, 2009, from http://ads.economist.com/the-economist/circulation/worldwide-circulation. 